Article

\title{
Exogenous Promoter Triggers APETALA3 Silencing through RNA-Directed DNA Methylation Pathway in Arabidopsis
}

\author{
Benqi Wang ${ }^{\circledR}$, Jie Liu, Lei Chu, Xue Jing, Huadong Wang, Jian Guo and Bin Yi * \\ National Key Laboratory of Crop Genetic Improvement, National Center of Rapeseed Improvement, \\ Huazhong Agricultural University, Wuhan 430070, China \\ * Correspondence: yibin@mail.hzau.edu.cn
}

Received: 30 July 2019; Accepted: 7 September 2019; Published: 11 September 2019

\begin{abstract}
The development of floral organs plays a vital role in plant reproduction. In our research, the APETALA3 (AP3) promoter-transgenic lines showed abnormal developmental phenotypes in stamens and petals. The aim of this study is to understand the molecular mechanisms of the morphological defects in transgenic plants. By performing transgenic analysis, it was found that the AP3-promoted genes and the vector had no relation to the morphological defects. Then, we performed the expression analysis of the class $\mathrm{A}, \mathrm{B}$, and $\mathrm{C}$ genes. A dramatic reduction of transcript levels of class $\mathrm{B}$ genes (AP3 and PISTILLATA) was observed. Additionally, we also analyzed the methylation of the promoters of class $\mathrm{B}$ genes and found that the promoter of AP3 was hypermethylated. Furthermore, combining mutations in $r d r 2-2, d r m 1 / 2$, and $n r p d 1 b-11$ with the AP3-silencing lines rescued the abnormal development of stamens and petals. The expression of $A P 3$ was reactivated and the methylation level of AP3 promoter was also reduced in RdDM-defective AP3-silencing lines. Our results showed that the RdDM pathway contributed to the transcriptional silencing in the transgenic AP3-silencing lines. Moreover, the results revealed that fact that the exogenous fragment of a promoter could trigger the methylation of homologous endogenous sequences, which may be ubiquitous in transgenic plants.
\end{abstract}

Keywords: AP3 promoter; methylation; RdDM; transcriptional silencing

\section{Introduction}

T-DNA insertion mutants of Arabidopsis are invaluable resource for studies of gene functions. [1]. However, the silencing of $35 S$ promoter-driven transgenes might occur in T-DNA (SALK, GABI, and FLAG) insertion mutants [2,3]. Studies have shown that some T-DNA transgene silencing of the $35 \mathrm{~S}$ promoter insertion is short-interfering RNAs (siRNA)-mediated [2]. In transgenic plants, the expression of a target gene or an endogenous gene is inhibited by the transfer of a foreign gene into a plant, but usually only affects the transferred gene and its endogenous gene and does not affect the expression of other genes. Plant transgenic silencing was first discovered in 1990 [4]. As the research has progressed, it is found that transgene silencing is universal and can even affect plant development.

Transgenic silencing triggered by epigenetic modifications in plants can be affected by small RNAs (sRNAs), both directly and in a mediated manner. sRNAs may mediate post-transcriptional gene silencing (PTGS), which is associated with the impairment of target RNA, and thus play an essential role in epigenetic gene regulation [5]. In plants, sRNAs are derived from cleavage of double-stranded RNA (dsRNA), which may trigger PTGS, and dsRNA can be made in the nucleus or cytoplasm. The dsRNA might originate from the transcription through IRs (inverted DNA repeats), an unlinked homologous transcribed locus, or an exogenous source, such as a single-stranded RNA (ssRNA) template catalyzed 
by RNA-dependent RNA polymerases (RdRP) [6]. Then, dsRNAs are processed into sense and antisense RNAs 21-25 nt long by RNase III-type protein termed Dicer, and the antisense small interfering RNA (siRNAs) are loaded into an argonaute family protein (ARGONAUTE 1 (AGO1)) to form RNA-induced silencing complex (RISC), which interacts with the homologous single-stranded mRNAs by pairing with the antisense siRNAs and then cleaves the mRNAs. The mRNAs cleaved by RISC may also be used as templates to form dsRNA, resulting in enhanced PTGS by increasing the level of siRNAs. Moreover, sRNAs produced in the cytoplasm can also enter the nucleus and trigger homologous DNA methylation [7]. AGO1 mainly acts in siRNA pathways for post-transcriptional gene silencing (PTGS), whereas AGO4 regulates transcriptional gene silencing (TGS). AGO4 regulates epigenetically silent states of repeated loci, transposons, and heterochromatin regions through its associated 24-nucleotide (nt) siRNAs [8]. RdDM is a key factor for the artificial induction of TGS [9]. Meanwhile, RdDM might be required for the initiation or maintenance of transcriptional silencing. Cytosine DNA methylation is a stable epigenetic mark and is important in many processes, including genomic imprinting, the silencing of transposons and genes, $X$ chromosome inactivation, and paramutation in plants $[10,11]$.

In Arabidopsis, DNA methylation occurs frequently in all three sequence kinds: The symmetric $\mathrm{CG}, \mathrm{CHG}$ contexts, and the asymmetric $\mathrm{CHH}$ context (in which $\mathrm{H}=\mathrm{A}, \mathrm{T}$, or $\mathrm{C}$ ). The establishment of DNA methylation is through the RdDM pathway [12]. Arabidopsis has at least three classes of DNA methyltransferase genes that are possibly involved in controlling RdDM: The DNA methyltransferase (MET) class, the chromomethylase (CMT) class, and the domains rearranged methyltransferase (DRM) class, among which MET1 maintains CG methylation [13], CMT3 maintains CHG methylation [14], while DRM2 catalyzes the de novo cytosine methylation in all three sequence kinds $[15,16]$. In the RdDM pathway, both 24nt siRNAs and long noncoding RNA transcripts are essential for de novo DNA methylation [11]. RNA Pol IV and Pol V, which respectively participate in catalyzing of the production of $24 \mathrm{nt}$ siRNAs and long noncoding RNA, have a distinct largest subunit (nuclear RNA polymerase D1 (NRPD1) and nuclear RNA polymerase E1 (NRPE1), respectively) while share some common subunits with Pol II [17,18]. siRNAs are produced from dsRNAs. Pol IV is recruited to transcribe transposons or some endogenous repeat loci, and the transcripts copied into dsRNAs by RNA-dependent RNA polymerase (RDR2) [19]. Dicer-like 3 (DCL3) cleaves the dsRNA into 24 nt siRNA duplexes and the siRNAs are subsequently methylated at their $3^{\prime}$ ends by the RNA methylase HUA-enhancer 1 (HEN1) for stabilization, and then one strand of the siRNAs is loaded into AGO4 to form an RISC [20]. On the other hand, Pol V is thought to transcribe the intergenic non-coding regions throughout the genome, the transcription is assisted by the DDR complex, including DRD1 (defective in RNA-directed DNA methylation 1), DMS3 (defective in meristem silencing 3), RDM1 (required for DNA methylation 1) and DMS4 [21,22]. RISC interacts with the Pol V subunit NRPE1 through the base-pairing of $24 \mathrm{nt}$ siRNAs with the nascent Pol V transcripts from the target loci [23,24], and then DRM2 is recruited to the region, which results in DNA methylation [23,25].

In Arabidopsis, class B genes are represented by AP3 and PI, which control the development of petals and stamens. Class B mutants develop sepals instead of petals in the second whorl, developing carpels rather than stamens in the third whorl [26-28]. AP3 contributes to the petal and stamen primordia, and the expression of $A P 3$ is maintained in these two parts during the subsequent floral development. Spatial and temporal restriction of $A P 3$ transcription is controlled via the interactions between proteins binding to different domains of the AP3 promoter [29]. In Arabidopsis, transgene silencing often occurs when silencing constructs are introduced (self-compatible IR or antisense (AS) orientations) or some T-DNA mutant lines are used. In our study, the transgenic lines (without IR or AS constructs) transformed from wild-type Arabidopsis also displayed an occurrence of transcriptional silencing.

To study the mechanism of tribenuron-methyl (TM)-induced male sterility in Arabidopsis and rapeseed (Brassica napus), we expressed TM resistance genes CYP81A6 [30] and csr (ALS point mutant) [31] under several promoters (unpublished). The majority of transgenic lines showed wild-type phenotype without TM treatments. Nevertheless, some of transgenic lines containing genes driven by the AP3 promoter showed some morphological defects, including lack of stamens 
and petals in Arabidopsis and wizened and smaller petals in rapeseed, which motivated the present study. To determine the mechanism underlying the defective phenotypes, we conducted a series of detailed biochemical and genetic analyses in Arabidopsis. The results show that the expression of AP3 is correlated with the hypermethylation of the AP3 promoter mediated by the RdDM pathway in the transgenic plants of Arabidopsis.

\section{Results}

\subsection{Defective Phenotypes Observed in the Transgenic Lines}

To investigate the contribution of tissue-specific expression of TM resistance genes for male sterility, we generated transgenic Arabidopsis lines carrying an insertion fragment (PCP or PCSR), which contained CYP81A6 or csr (dominant mutation of CSR) genes under the control of the Arabidopsis AP3 promoter (Figure 1A, Supplementary Figure S5). Arabidopsis thaliana transgenic materials M17 and M43 (Table S2) and rapeseed transgenic materials $\mathrm{BnP1}$, BnP2, BnP3, BnP4, and BnP5 were used as experimental materials in this study. In Arabidopsis with M17 as a phenotype, as shown in Figure 1C,G, compared with wild type (Figure 1B,F), the main inflorescences were not elongated, and the second round of petals and the third round of stamen development were defective. For example, BnP1 in Brassica napus L. (Figure 1E,I) showed no significant difference in the overall appearance of the inflorescence compared to the wild type (Figure 1D,H), but the flowers were small and the petals were small and shrunk. We designated the abnormal phenotypes, which were similar to that of ap3-3 mutant, as ap3-like phenotypes. T2 plants (ap3-like phenotypes) were genotyped by genomic PCR. The results demonstrated that half of the plants harbored the insertion fragments and showed ap3-like phenotypes defects. By cross pollination with pollens from wild-type Arabidopsis flowers, Some of the transgenic lines of rapeseed, which also contained PCP or PCSR constructs, showed similar defects, such as shriveled and smaller petals, less fertile stamens, which produce lesser pollen, and smaller siliques compared with ZYWT (wild type) (Figure 1E,I). We used the TAIL-PCR technique to perform flanking sequence analysis on the transgenic plant M17. According to the results of the flanking sequence analysis, it was found that the exogenous fragment was inserted into the exon of At1g35146, and the subsequent PCR identification of the M17 progeny was based on this. 
A
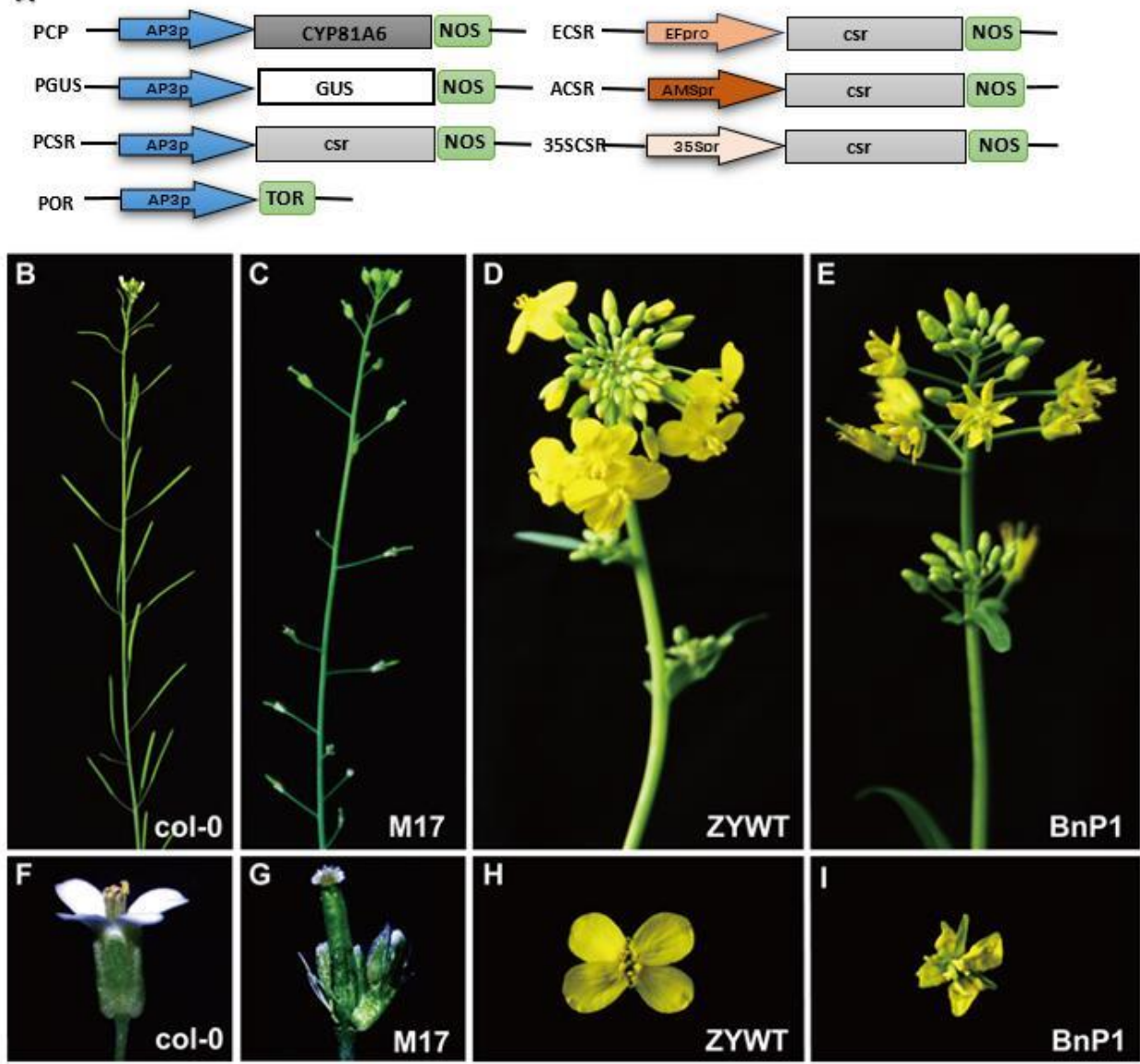

$J$

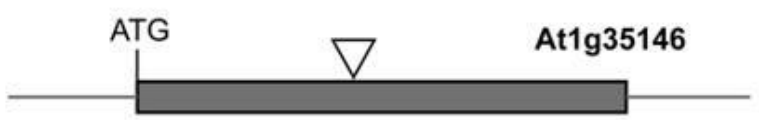

Figure 1. (A) Schematic illustration of constructs used to transform Arabidopsis and rapeseed. Arrows indicate the promoters. The fragments were cloned to the expression sites of $p C A M B I A 2300 ;(\mathbf{B})$ feature of a wild silique of Arabidopsis; (C) feature of a male sterile transgenic line without petals and stamens of Arabidopsis; (D) rapeseed with normal inflorescence; (E) transgenic inflorescence of rapeseed (BnP1) with defective petals; (F) a wild flower with normal petals of Arabidopsis; (G) a male sterile transgenic Arabidopsis flower without petals and anthers on top of a filament; $(\mathbf{H})$ a wild flower of rapeseed; (I) a transgenic flower of rapeseed (BnP1) with wizened petals; (J) DNA insertion occurred in the exon of At1g35146 based on the results from TAIL-PCR analysis. Grey box: Exon; grey lines: Intergenic sequences; black triangles: Location of transgenes.

In BnP1 (containing PCSR construct) flowers, scanning electron micrograph showed that the petals had irregularly shaped but elongated epidermal cells and stomas (Figure 2B), while the cells in wild plant flowers were well-organized and closely arranged (Figure 2A).

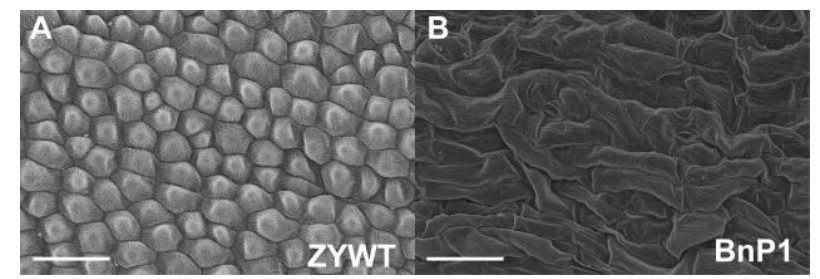

Figure 2. Scanning electron micrograph. (A) A wild flower with normal petals of B. napus; (B) a transgenic line $(\mathrm{BnP1})$ with irregularly shaped cells in petals. Bars $=50 \mu \mathrm{m}$. 


\subsection{Exogenous AP3 Promoter was Responsible for the ap3-Like Phenotypes}

To investigate the association of this chimeric gene with the ap3-like phenotypes, the PGUS construct that contained the $\beta$-glucuronidase (GUS) and the construct (POR) without genes driven by the AP3 promoter were prepared and transformed into Arabidopsis, respectively (Figure 1A). Some of both PGUS and POR transgenic lines showed ap3-like phenotypes, indicating that these chimeric genes (the TM resistance genes, the GUS gene, or even no gene driven) were not the major controlling elements.

It was unclear whether the vector or selectable marker was responsible for the ap3-like phenotypes. Hence, we cloned the PCSR fragment into $p C A M B I A 1300$ and PBI121 vectors. Some of both the two transgenic lines showed the ap3-like phenotypes. We also transformed the $p C A M B I A 2300$ vector into Arabidopsis plants, but the transgenic lines did not show any morphological defects. In order to exclude the possibility that the selectable marker was responsible for the phenotypes, the PGUS fragment was transformed into Arabidopsis plants using the double right-border (DRB) T-DNA binary vector that was provided by Prof Yongjun Lin (National Key Laboratory of Crop Genetic Improvement, Huazhong Agricultural University, Wuhan, China), to generate marker-free transgenic lines. Seventeen of 28 transgenic lines displayed ap3-like phenotypes. The sterile transgenic lines were crossed with the wild type to generate posterity lines, which may have contained the PGUS or the selectable marker gene fragment, respectively. Only lines that carried the PGUS fragment showed ap3-like phenotypes. These results suggested that the vector or selectable marker was not responsible for the ap3-like phenotypes.

From these transformation results, we found that all the transgenic lines with ap3-like phenotypes may contain the AP3 promoter (Supplementary Figure S4). To determine whether the AP3 promoter was the major controlling element for the morphological defects, a series of constructs were generated and transformed into Arabidopsis plants (Figure 1A). The constructs contained csr driven by the 35S (cauliflower mosaic virus), EF, or $A M S$ promoter, and all the transgenic lines did not show any ap3-like phenotypes, suggesting that it was the $A P 3$ promoter rather than the $35 S, E F$, or $A M S$ promoter that was the major controlling element for ap3-like phenotypes.

\section{3. ap3-Like Phenotypes were Correlated with the DNA Hypermethylation of AP3 Promoter}

In comparison with Col-0 and M42, M17 and M43 showed a sharp decline of AP3 expression. Additionally, we compared the AP3 expression in rapeseed (petals) and a similar result was obtained. The phenotypic defects of $\mathrm{BnP} 1$ and $\mathrm{BnP} 2$ are more serious, while the phenotypes of $\mathrm{BnP} 3, \mathrm{BnP} 4$, and $\mathrm{BnP5}$ are weaker, and the expression of $A P 3$ gradually decreases with the severity of phenotypic defects (Figure 3A). To examine the cause of the ap3-like phenotypes in the Arabidopsis, as the transgenic results showed that it was the AP3 promoter that was responsible for the ap3-like phenotypes, we wanted to confirm that whether the AP3 expression (inflorescences) was changed in the ap3-like phenotypes transgenic lines of Arabidopsis; therefore, we carried out expression analysis of AP3 in wild-type Arabidopsis plants (Col-0), in M17 and M43 (transgenic lines with obvious morphological defects) and in M42 (transgenic lines without any defects) (Figure 3B). 

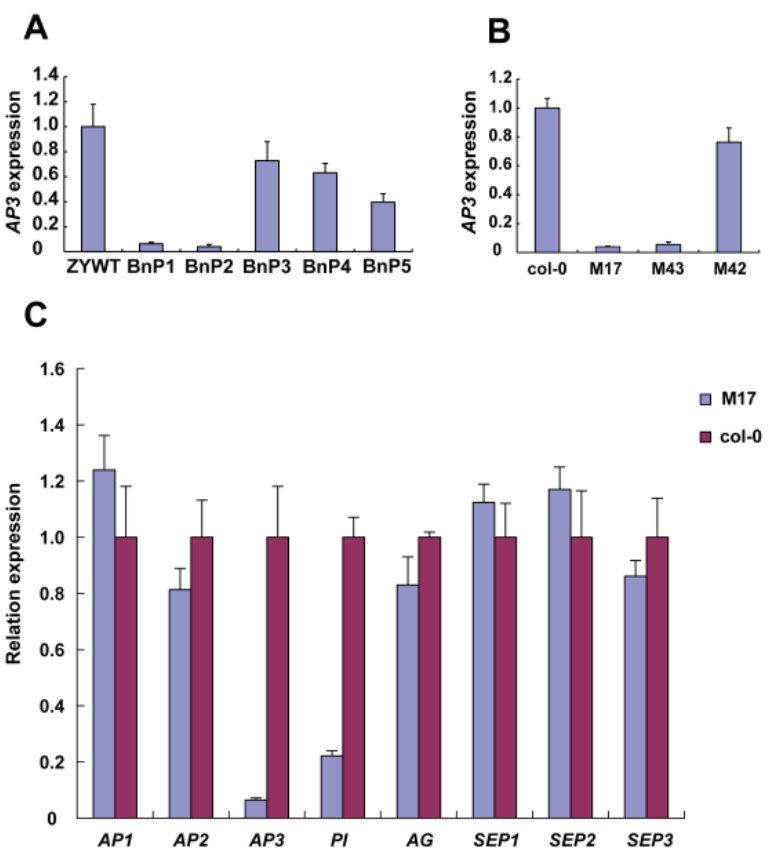

Figure 3. RT-PCR analysis of selected target genes. (A) AP3 expression of transgenic rapeseed BnP1 and $\mathrm{BnP} 2$ with severe morphological defects and $\mathrm{BnP} 3, \mathrm{BnP} 4$, and $\mathrm{BnP} 5$ with slight morphological defects, ZYWT (wild-type); (B) AP3 expression of transgenic Arabidopsis M17, M43 with morphological defects, and M42 with no defects, Col-0 (wild plant)(http://katahdin.mssm.edu/kismeth/revpage.pl) [32-34]; (C) the levels of class A, B, and C transcripts. All the rapeseed (P1-P5) and Arabidopsis (M17, M42, M43) transgenic lines contain the PCSR construct. The expression levels were controlled using the signal from the ACTIN gene. The average $( \pm \mathrm{SD})$ values are shown from three biological duplicates of quantitative reverse transcription PCR.

Furthermore, real-time RT-PCR was carried out to determine the expression of class A, B, and $\mathrm{C}$ genes in Arabidopsis (inflorescences). The results show that for class $\mathrm{A}$ and $\mathrm{C}$ genes, no expression difference was observed between M17 and Col-0 (Figure 3C), while AP3 and PI showed a sharp decrease of expression in M17. These results suggest that the decrease of AP3 and PI expression might be responsible for the observed phenotypes. To determine whether the genes around the AP3 region were influenced in the transgenic lines with ap3-like phenotypes, we compared the expression levels of these genes between Col-0 and M17 flowers (Supplementary Figure S1). The data suggest that there is no difference in gene expression between them. Together, these results indicate that it is class B homeotic genes rather than class $\mathrm{A}$ or $\mathrm{C}$ genes that are necessary for the development of sepals and petals, and the genes around AP3 are not influenced in the transformation.

Based on the above results, we speculated that the ap3-like phenotypes were triggered by epigenetic modifications. In order to clarify the cause of the morphological defects, we performed the DNA methylation analysis of AP3 promoter in Col- 0 and M17 by bisulfite sequencing in Arabidopsis (inflorescences). The results showed that the DNA methylation of $A P 3$ promoter was detected at low levels in Col-0, while a high level of DNA methylation at all sequence contexts (CG, CHG, and CHH) was found in M17 (Figure 4A). The DNA methylation level of AP3 promoter was less than $50 \%$ when only one of the AP3 promoters (exogenous and endogenous) was methylated, while the results showed that the methylation all of CG, CHG, and $\mathrm{CHH}$ sites covered $50 \%$, so both exogenous and endogenous AP3 promoters were hypermethylated, which is consistent with ap3-like phenotypes and the AP3 expression of M17. Additionally, we also performed DNA methylation analysis on the PI promoter. The results suggest that DNA methylation of PI promoter was not observed at all three cytosine contexts in M17 and Col-0 (Figure 4B), which is opposite to the level of PI expression. The probable reason for the lack of $P I$ transcripts in the flowers with ap3-like phenotypes was that the AP3 expression 
is absent. We also found that the initial pattern of PI expression was normal in ap3-3 flowers; thus, high levels of PI RNA are not maintained after stage 4 or 5 in ap3-3 flowers. The results show that both $A P 3$ and $P I$ are involved in the regulation of PI expression, whereas neither is required for the initiation of PI expression [35]. Taken together, these results show that the DNA methylation of AP3 promoter is responsible for the defective flower development in M17.

\section{A}

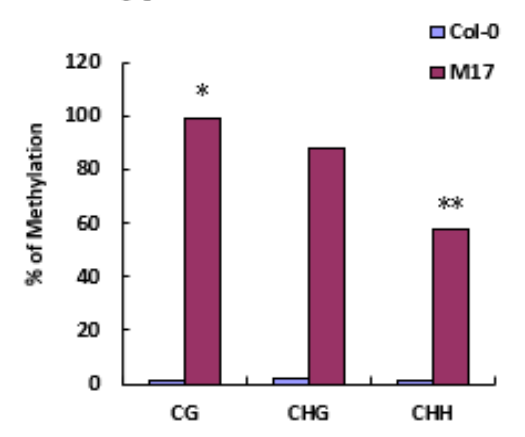

B

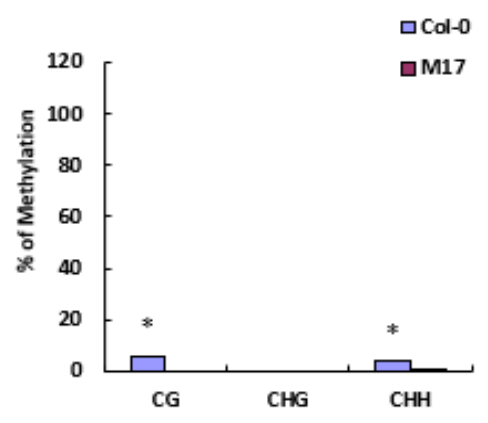

Figure 4. DNA methylation analysis of Col-0 and M17 by bisulfite sequencing. (A) DNA methylation analysis of $A P 3$ promoter (B) DNA methylation analysis of $P I$ promoter. The percentage of methylation on $\mathrm{CG}, \mathrm{CHG}$, and $\mathrm{CHH}$ sites are shown and $\mathrm{T}$ test analysis of methylation differences in the group $\left({ }^{*} p<0.05,{ }^{* *} p<0.01\right)$.

To further confirm that the DNA methylation of AP3 promoter is responsible for the ap3-like phenotypes in M17, a complementation test was conducted as follows: M17 was crossed with null mutants sgs3-11 and $r d r 6-11$ as SGS3 and RDR6 are required for PTGS [36]; M17 was also crossed with $r d r 2-2, d r m 1 / 2$, and nrpd1b-11, which release the silencing of a reporter gene through the RdDM pathway. Among the examined F1 plants, lines with the PCSR construct showed the same phenotypes as M17. Then, double heterozygous plants (identified by genomic PCR) were chosen to be pollinated with pollens from the null mutants. In the $\mathrm{BC} 1$ generation, the morphological defects were fully complemented only in the lines with $r d r 2-2, d r m 1 / 2$, and $n r p d 1 b-11$ as the pollen donors (Figure $5 \mathrm{~A}$ ), whereas those lines containing $r d r 6-11$ and sgs3-11 homozygote were not recovered due to fact that SGS3 and RDR6 were not present in the pathway of RdDM. We also analyzed the AP3 expression, PI expression, and DNA methylation levels of $A P 3$ promoter by bisulfite sequencing in the complementation lines. In comparison with M17, the high methylation of the AP3 promoter was substantially decreased at all the three cytosine contexts (CG, CHG, and $\mathrm{CHH}$ ), and the reduced expression of AP3 and PI were rescued in the complementation lines (Figure $5 B, C$ ). These results suggest that the morphological defects were controlled by RdDM. It was possible that the transgenic construct of AP3 promoter may have generated siRNA and caused the DNA methylation of the AP3 promoters, resulting in the decrease of $A P 3$ expression and obvious defects in floral morphology. 
A
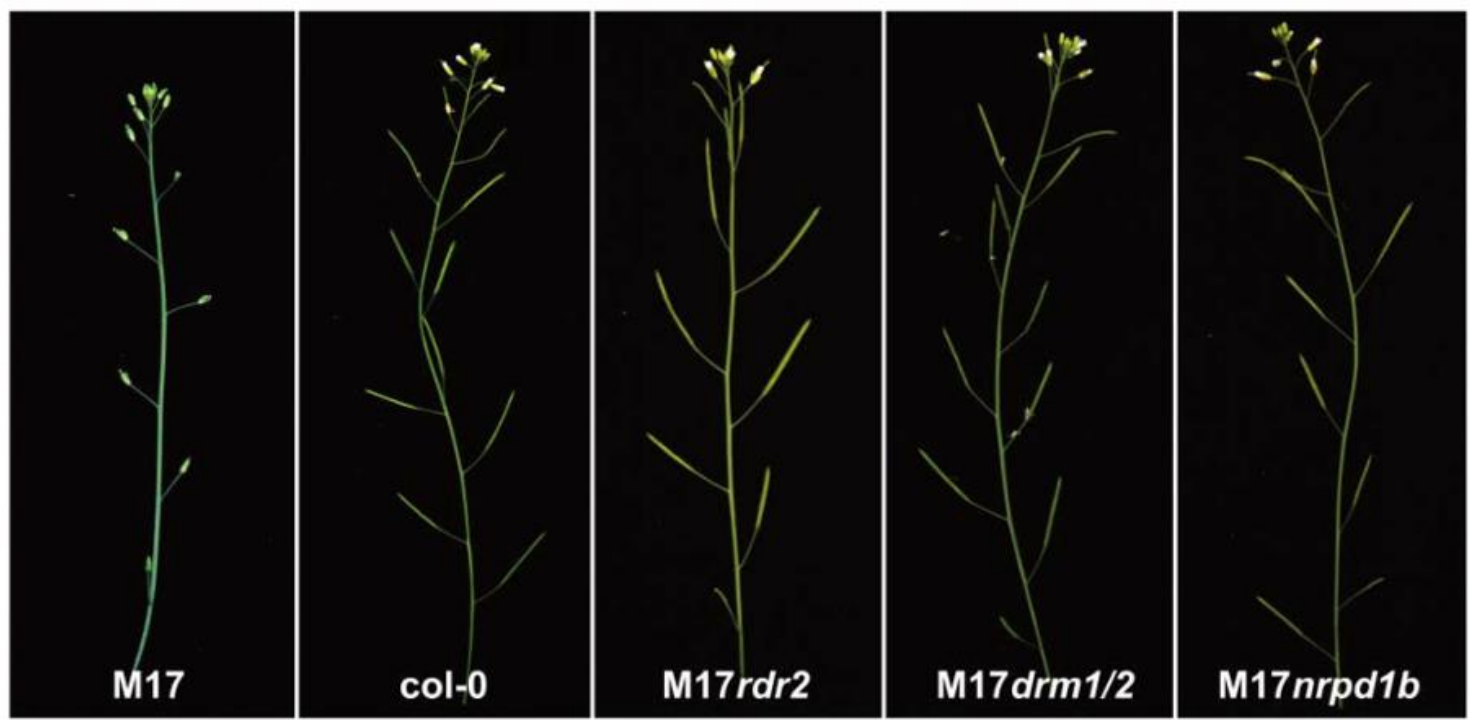

B

C
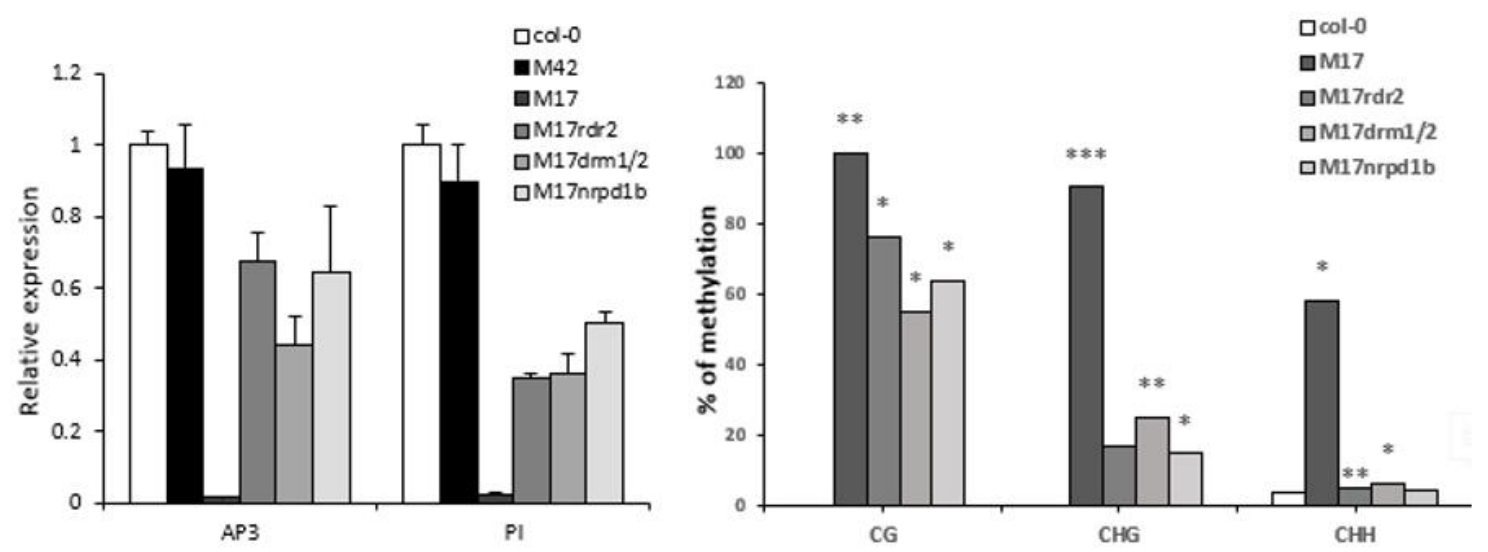

Figure 5. Complementation test for M17 transgenic lines. (A) All the morphological defects including sepaloid petals and absence of anthers in M17 were rescued in complementation lines; (B) RT-PCR analysis of the expression of AP3 and PI in M17 and complementation lines; (C) cytosine DNA methylation analysis of transgenic, which is endogenous AP3 promoters in M17 and complementation lines by bisulfite sequencing and $\mathrm{T}$ test analysis of methylation differences in the group ${ }^{*} p<0.05$, ** $\left.p<0.01,{ }^{* * *} p<0.001\right)$. The expression levels were controlled using the signal from the ACTIN gene. The average $( \pm \mathrm{SD})$ values are shown from three biological duplicates of quantitative reverse transcription PCR.

\section{Discussion}

3.1. Exogenous AP3 Promoter may Trigger the Hypermethylation of AP3 Promoter Mediated by RdDM in Transgenic Arabidopsis Plants

Epigenetic silencing is important for gene regulation during plant development and for the inactivation of viruses, transposons, or genes. DNA methylation is an important epigenetic marker conserved in plants, mammals, and some fungi for transcriptional gene silencing (TGS) in diverse organisms [37,38]. De novo cytosine methylation can be catalyzed in a pathway known as RdDM. The RdDM pathway is of central importance to the initiation and maintenance of TGS in plants [10]. In this study, our analysis of the DNA methylation in the AP3 promoter of the transgenic Arabidopsis plants show that the transgenic homologous AP3 promoter affected the overall methylation of 
exogenous and endogenous AP3 promoters, as indicated by the strong correlation between the decrease of $A P 3$ transcripts in transgenic lines with ap3-like phenotypes and a high level of overall methylation of AP3 promoter (Figures 3 and 4), and the transformation results in Arabidopsis indicated that in transgenic lines it was the AP3 promoter triggering the ap3-like phenotypes. These results suggest that the exogenous AP3 promoter plays an important role in regulating the TGS of AP3. However, gene-silencing phenomena might occur at the post-transcriptional level, which involved mRNA specific degradation in the cytoplasm or the methylation of coding sequences [39,40]. Several reports have shown that PTGS can not only affect transgenes that are homologous to endogenous genes, but also transgenes that are not homologous to endogenous genes, suggesting that the PTGS is not a simple regulatory mechanism affecting endogenous gene expression [41-43]. We also speculated that the decrease of AP3 expression is related to PTGS. SGS3 and RDR6 are required for the biosynthesis of trans-acting siRNAs, and they initiate PTGS or trigger DNA methylation [36,44]. However, BC1 transgenic lines that contained sgs3-11 or $r d r 6-11$ homozygote showed no morphological alterations. On the other hand, the BC1 transgenic lines with $r d r 2-2, d r m 1 / 2$, and $n r p d 1 b-11$ as the pollen donors showed no defects in floral morphology as well as a reduced the DNA methylation level (Figure 5). These findings suggest that RdDM is required for the silencing of AP3. Furthermore, the phenotype of the complementation lines containing $r d r 6-11$ and sgs3-11 homozygote was not recovered, suggesting that the silencing of AP3 is not related to PTGS.

PTGS and TGS were considered to be the major pathways of epigenetic regulation, and both of them might be associated with methylation. Recent studies have already indicated that transgenes silencing might accompany methylation, transgenic lines of Nicotiana attenuata displayed a variable occurrence of transgene silencing, and bisulfite sequencing analysis indicated a hypermethylation within the $35 S$ and NOS promoters of these lines [45]. The RNA interference (RNAi) induces gene silencing accompanied with methylation by an IR directed at the promoter or coding sequence [46]. The hypermethylation of AP3 promoter found in M17 containing an extra copy of AP3 promoter was consistent with those who found that unwanted transgenes silencing was commonly associated with hypermethylation within the promoter regions of transgene (Figure $4 \mathrm{~A}$ ).

\subsection{The ap3-like Phenotypes was Inherited}

We combined phenotypes of transgenic plant by crossing transgenic line (M17) and wild-type, the offspring of which harbored the transgenes that showed ap3-like phenotypes, suggesting that the transgenic silencing might be inherited, similar as reported for $N$. attenuate, which showed loss of hygromycin resistance and a drastic down-regulation of antimicrobial peptide gene expression in the T3 generation of transgenic N. attenuate [45]. However, the gene inactivation that occurred in plants with multicopy integration of the foreign DNA and transgene silencing would be reactivated by crossing with wild-type plants [47]. In our case, the ap3-like phenotypes did not change in the offspring of several regenerants, probably because the methylation levels had already accumulated in $\mathrm{T} 1$ plants and the foreign AP3 promoter existing in the offspring might trigger the de novo cytosine methylation.

\subsection{The Characteristic of AP3 Promoter Methylation in Plants with ap3-Like Phenotypes}

It was previously reported that TGS is induced by RdDM following methylation that spreads from the originally targeted region to the adjacent regions [48]. In contrast, in M17, the genes around the AP3 region did not show any change in expression level (Supplementary Figure S1). These results suggest that the extraneous fragment only influences the TGS of homologous regions but does not affect that of nonhomologous regions. TGS with methylated promoters frequently have tissue-specific expression patterns [49]. Nevertheless, in our study, methylated AP3 promoter did not show tissue-specific patterns, as indicated by the DNA methylation analysis using leaves, stems, and inflorescences, all of which showed hypermethylation in AP3 promoter sequences (Supplementary Figure S2). Direction of RdDM to a promoter sequences can lead to the occurrence of TGS. These data suggest that the high 
DNA methylation of $A P 3$ promoter has an obvious effect on the regulation of $A P 3$ gene transcription and the ap3-like phenotypes (Figures 2B and 3A).

Our discovery of the way that exogenous fragment triggers DNA methylation of homologous sequences may be extended to all other transgenic events. The phenomenon occurred not only in Arabidiopsis, but also in rapeseed in our transgenic experiments (Figure 1B-I and Figure 2A,B), indicating that it may occur in more plants. Exogenous fragment in plants may trigger the silencing of endogenous sequences.

\subsection{An Objective View on Transgenes Silencing}

As our results indicate, the extraneous AP3 promoter has an important role in gene silencing, which is controlled by RdDM. In many transgenic studies, some unexpected phenotypes derived from TGS might be obtained. A previous study has shown that transcriptional silencing was mediated by the $35 \mathrm{~S}$ promoter homologous between transgenes and the T-DNAs (such as the SALK, FLAG, and GABI) used for insertional mutagenesis [3]. Transgene silencing phenomena may occur when there are multiple copies of a particular sequence in a genome and the silencing results from interactions between homologous sequences [50,51]. In our studies, transcriptional silencing was accompanied by hypermethylation in the AP3 promoter in transgenic Arabidiopsis plants, similar to reports that silencing often occurs when the genome existed in the transgene, which was homologous to endogenous sequences [50]. So, care must be taken to control for unwanted silencing when studying expression of transgenes, as it might trigger transgene silencing when the transgenic construct used and the genome share regions of homology. More molecular biological analyses should be carried out to determine whether exogenous fragments induce TGS of the homologous regions in plants. When the transgenic lines display unwanted or unexpected phenotypes, it does not necessarily mean that the gene has no function as the genes cannot be transcribed normally. In transgenic studies, it is imperative to conduct more experiments to determine whether the construct is stably transformed into the plants; real-time RT-PCR analysis should be conducted to analyze the gene expression and Southern blotting should be taken to detect the insertion number, and more complementation tests should be conducted to confirm whether the gene silencing is responsible for the observed phenotypes.

\section{Materials and Methods}

\subsection{Plant Materials}

The mutant alleles of $r d r 2-2, d r m 1 / 2, n r p d 1 b-11, r d r 6-11$, and sgs3-11 [44] used in this study were in a Columbia (Col-0) genetic background. M42, M43, and M17 were the transgenic Arabidopsis lines with the PCSR constructs containing the $1.2 \mathrm{~Kb} A P 3$ promoter. Plants were grown in a growth chamber or controlled temperature at $23^{\circ} \mathrm{C}$ with $16 \mathrm{~h}$ of light and $8 \mathrm{~h}$ of darkness. The rapeseed (cv. Zheyou 50) was grown in soil under natural conditions. $\mathrm{BnP1}, \mathrm{BnP} 2, \mathrm{BnP} 3, \mathrm{BnP} 4$, and $\mathrm{BnP} 5$ were transgenic lines (contain PCSR constructs) of rapeseed.

\subsection{Vector Construction and Expression of csr or CYP81A6 in Arabidiopsis and Rapeseed}

The AP3, EF, and AMS promoter fragments were amplified from Arabidiopsis. The cauliflower mosaic virus (CaMV) $35 \mathrm{~S}$ promoter was amplified from $p C A M B I A 2300$. The products were cloned into the $p C A M B I A 2300, p C A M B I A 1300$, or PBI121 vector. All binary vector expression constructs were transferred to Agrobacterium tumefaciens strain GV3101 by electroporation and were transformed into Col-0 and Zheyou 50 plants using the methods previously described [52].

\subsection{Scanning Electron Micrograph}

SEM was used to study the surface of petals of the wild-type and transgenic rapeseed plants. Fresh petals from 4-7 mm buds were collected and fixed in $2 \%$ glutaraldehyde overnight. The ensuing procedures were performed as previously reported [53]. 


\subsection{RNA Isolation and Real-Time RT-PCR}

Total RNA was isolated from inflorescences (Arabidopsis) and petals (rapeseed) using Trizol (Bioteke, Beijing, China) according to the manufacturer's instructions. DNase treatment was performed on total RNA to remove the genomic DNA contamination, and then the RNA was used for first strand cDNA synthesis using a SuperScript II kit (Invitrogen, Carlsbad, CA, USA) following the manufacturer's protocol with an oligo $(\mathrm{dT})_{18}$ primer. The derived cDNA was used as template for real-time RT-PCR analysis. Quantitative PCR was performed with SYBR Green Realtime PCR Master Mix (TOYOBO, Osaka, Japan). ACTIN mRNA was detected in parallel and controlled data normalization. The primers used for quantitative PCR are listed in Supplementary Table S1.

\subsection{DNA Methylation Analysis}

Fresh tissues (inflorescences, stems, and leaves) were collected for genomic DNA isolation. DNA methylation analysis was performed by the bisulfite sequencing method [54]. The DNA was isolated using the DNeasy Plant Mini Kit (Qiagen, Hilden, Germany). Bisulfite sequencing was performed, and 600-800 ng of DNA was sodium-bisulfite converted and purified using the EpiTect Bisulfite Kit (Qiagen, Hilden, Germany) according to the manufacturer's instructions. Treated DNAs were used for PCR amplification of different loci using rTaq DNA polymerase (Takara, Tokyo, Japan), PCR conditions were as follows: $94{ }^{\circ} \mathrm{C}, 5 \mathrm{~min} ; 38$ cycles of $\left(94{ }^{\circ} \mathrm{C}, 45 \mathrm{~s} ; 48^{\circ} \mathrm{C}, 30 \mathrm{~s} ; 72{ }^{\circ} \mathrm{C}, 30 \mathrm{~s}\right) ; 72{ }^{\circ} \mathrm{C}, 10 \mathrm{~min}$. The PCR products generated using two primer pairs from the promoters of $A P 3$ and PI were of identical size (the -486 to -228 promoter fragment of $A P 3$ and -794 to -465 promoter fragment of $P I$ ) in M17 and Col-0. PCR products were cloned into the pMD18-T vector (Takara, Tokyo, Japan), and individual clones were sequenced. For the DNA methylation analysis, 6-8 clones of each sample were sequenced. Data analysis and primers design were performed using the online tool. The degree of conversion was determined by sequencing a region of the PHAVOLUTA locus [55]. The bisulfite conversion rate for the sample was over 99\%. Primers used for bisulfite sequencing are described in Supplementary Table S1.

\subsection{Transgenic and SALK Lines Analyses}

Homozygous SALK lines were identified by PCR genotyping to determine whether T-DNA insertion exists. Total genomic DNA samples were extracted using the fresh leaves of plants. TAIL-PCR technique was used to determine the insertion position of the PCSR construct in M17 (At1g35146) (Figure 1I). We designed the primers for identifying the transgenic lines: One primer specific to the region around the inserted fragment, and one corresponding to a constitutively expressed kanamycin gene. The plants of $\mathrm{BC} 1$ generation were genotyped by genomic $\mathrm{PCR}$, and plants harboring the PCSR construct and the T-DNA insertion from null mutants were subjected to morphological observations, real-time RT-PCR, and DNA methylation analysis. Progenies of this backcross were allowed to self-pollinate. The primers used for transgenic lines analysis are listed in Supplementary Table S1.

\section{Conclusions}

Through all of the above experiments, we revealed the fact that exogenous fragments of the promoter can trigger methylation of homologous endogenous sequences, which may be ubiquitous in transgenic plants.

Supplementary Materials: Supplementary materials can be found at http://www.mdpi.com/1422-0067/20/18/ $4478 / \mathrm{s} 1$.

Author Contributions: B.W. and B.Y. designed and performed experiments, analyzed data, and wrote the manuscript. J.L., L.C., X.J., H.W. and J.G. help research and article revision. Y.B. provided suggestions, funds and experimental conditions.

Funding: This project was supported by the Natural Science Foundation of China (Grant No. 31371488, 30900904) and the National High Technology Research and Development Program of China (Grant No. 2012AA101107). 
Acknowledgments: We thank Yijun Qi for providing various mutants, Lun Zhao and Changbin Gao for helpful discussions.

Conflicts of Interest: The authors declare that they have no conflict of interest.

\section{References}

1. Matsunaga, W.; Shimura, H.; Shirakawa, S.; Isoda, R.; Inukai, T.; Matsumura, T.; Masuta, C. Transcriptional silencing of $35 \mathrm{~S}$ driven-transgene is differentially determined depending on promoter methylation heterogeneity at specific cytosines in both plus- and minus-sense strands. BMC Plant Biol. 2019, 19, 24. [CrossRef] [PubMed]

2. Mlotshwa, S.; Pruss, G.J.; Gao, Z.; Mgutshini, N.L.; Li, J.; Chen, X.; Bowman, L.H.; Vance, V. Transcriptional silencing induced by Arabidopsis T-DNA mutants is associated with 35S promoter siRNAs and requires genes involved in siRNA-mediated chromatin silencing. Plant J. 2010, 64, 699-704. [CrossRef] [PubMed]

3. Daxinger, L.; Hunter, B.; Sheikh, M.; Jauvion, V.; Gasciolli, V.; Vaucheret, H.; Matzke, M.; Furner, I. Unexpected silencing effects from T-DNA tags in Arabidopsis. Trends Plant Sci. 2008, 13, 4-6. [CrossRef] [PubMed]

4. Napoli, C.; Lemieux, C.; Jorgensen, R. Introduction of a Chimeric Chalcone Synthase Gene into Petunia Results in Reversible Co-Suppression of Homologous Genes in trans. Plant Cell 1990, 2, 279. [CrossRef] [PubMed]

5. Vaucheret, H.; Béclin, C.; Fagard, M. Post-transcriptional gene silencing in plants. J. Cell Sci. 2001, 114, 3083-3091. [PubMed]

6. Wassenegger, M. The role of the RNAi machinery in heterochromatin formation. Cell 2005, 122, 13-16. [CrossRef] [PubMed]

7. Matzke, M.; Matzke, A.J.; Kooter, J.M. RNA: Guiding gene silencing. Science 2001, 293, 1080-1083. [CrossRef] [PubMed]

8. Wang, H.; Zhang, X.; Liu, J.; Kiba, T.; Woo, J.; Ojo, T.; Hafner, M.; Tuschl, T.; Chua, N.H.; Wang, X.J. Deep sequencing of small RNAs specifically associated with Arabidopsis AGO1 and AGO4 uncovers new AGO functions. Plant J. 2011, 67, 292-304. [CrossRef]

9. Wakasa, Y.; Kawakatsu, T.; Harada, T.; Takaiwa, F. Transgene-independent heredity of RdDM-mediated transcriptional gene silencing of endogenous genes in rice. Plant Biotechnol. J. 2018, 16, 2007-2015. [CrossRef]

10. Zhang, H.; Zhu, J.-K. RNA-directed DNA methylation. Curr. Opin. Plant Biol. 2011, 14, 142-147. [CrossRef] [PubMed]

11. Law, J.A.; Jacobsen, S.E. Establishing, maintaining and modifying DNA methylation patterns in plants and animals. Nat. Rev. Genet. 2010, 11, 204-220. [CrossRef] [PubMed]

12. Mahfouz, M.M. RNA-directed DNA methylation: Mechanisms and functions. Plant Signal. Behav. 2010, 5, 806. [CrossRef] [PubMed]

13. Dinh, T.T.; O’Leary, M.; Won, S.Y.; Li, S.; Arroyo, L.; Liu, X.; Defries, A.; Zheng, B.; Cutler, S.R.; Chen, X. Generation of a luciferase-based reporter for $\mathrm{CHH}$ and CG DNA methylation in Arabidopsis thaliana. Silence 2013, 4, 1. [CrossRef] [PubMed]

14. Cao, X.; Aufsatz, W.; Zilberman, D.; Mette, M.F.; Huang, M.S.; Matzke, M.; Jacobsen, S.E. Role of the DRM and CMT3 Methyltransferases in RNA-Directed DNA Methylation. Curr. Biol. 2003, 13, 2212-2217. [CrossRef] [PubMed]

15. Cao, X.; Jacobsen, S.E. Role of the Arabidopsis DRM Methyltransferases in De Novo DNA Methylation and Gene Silencing. Curr. Biol. 2002, 12, 1138-1144. [CrossRef]

16. Moritoh, S.; Eun, C.H.; Ono, A.; Asao, H.; Okano, Y.; Yamaguchi, K.; Shimatani, Z.; Koizumi, A.; Terada, R. Targeted disruption of an orthologue of DOMAINS REARRANGED METHYLASE 2, OsDRM2, impairs the growth of rice plants by abnormal DNA methylation. Plant J. 2012, 71, 85-98. [CrossRef] [PubMed]

17. Lahmy, S.; Bies-Etheve, N.; Lagrange, T. Plant-specific multisubunit RNA polymerase in gene silencing. Epigenetics 2010, 5, 4-8. [CrossRef] [PubMed]

18. Zheng, B.; Wang, Z.; Li, S.; Yu, B.; Liu, J.-Y.; Chen, X. Intergenic transcription by RNA polymerase II coordinates Pol IV and Pol V in siRNA-directed transcriptional gene silencing in Arabidopsis. Genes Dev. 2009, 23, 2850-2860. [CrossRef]

19. Henderson, I.R.; Jacobsen, S.E. Epigenetic inheritance in plants. Nature 2007, 447, 418-424. [CrossRef] 
20. Haag, J.R.; Pikaard, C.S. Multisubunit RNA polymerases IV and V: Purveyors of non-coding RNA for plant gene silencing. Nat. Rev. Mol. Cell Biol. 2011, 12, 483-492. [CrossRef]

21. Huang, C.-F.; Zhu, J.-K. RNA Splicing Factors and RNA-Directed DNA Methylation. Biology 2014, 3, $243-254$. [CrossRef] [PubMed]

22. Law, J.A.; Ausin, I.; Johnson, L.M.; Vashisht, A.A.; Zhu, J.-K.; Wohlschlegel, J.A.; Jacobsen, S.E. A Protein Complex Required for Polymerase V Transcripts and RNA-Directed DNA Methylation in Arabidopsis. Curr. Biol. 2010, 20, 951-956. [CrossRef] [PubMed]

23. Lee, T.; Gurazada, S.; Zhai, J.; Li, S.; Simon, S.A.; Matzke, M.A.; Chen, X.; Meyers, B.C. RNA polymerase V-dependent small RNAs in Arabidopsis originate from small, intergenic loci including most SINE repeats. Epigenetics. 2012, 7, 781-795. [CrossRef] [PubMed]

24. Zheng, Q.; Rowley, M.J.; Böhmdorfer, G.; Sandhu, D.; Gregory, B.D.; Wierzbicki, A.T. RNA polymerase V targets transcriptional silencing components to promoters of protein-coding genes. Plant J. 2013, 73, 179-189. [CrossRef] [PubMed]

25. Zhang, H.; Zhu, J.-K. Seeing the forest for the trees: A wide perspective on RNA-directed DNA methylation. Genes Dev. 2012, 26, 1769-1773. [CrossRef] [PubMed]

26. Krizek, B.A.; Fletcher, J.C. Molecular mechanisms of flower development: An armchair guide. Nat. Rev. Genet. 2005, 6, 688-698. [CrossRef] [PubMed]

27. Theissen, G.; Melzer, R. Molecular mechanisms underlying origin and diversification of the angiosperm flower. Ann. Bot. 2007, 100, 603-619. [CrossRef] [PubMed]

28. Wuest, S.E.; O’Maoileidigh, D.S.; Rae, L.; Kwasniewska, K.; Raganelli, A.; Hanczaryk, K.; Lohan, A.J.; Loftus, B.; Graciet, E.; Wellmer, F. Molecular basis for the specification of floral organs by APETALA3 and PISTILLATA. Proc. Natl. Acad. Sci. USA 2012, 109, 13452-13457. [CrossRef] [PubMed]

29. Hill, T.A.; Day, C.D.; Zondlo, S.C.; Thackeray, A.G.; Irish, V.F. Discrete spatial and temporal cis-acting elements regulate transcription of the Arabidopsis floral homeotic gene APETALA3. Development 1998, 125, 1711-1721. [PubMed]

30. Pan, G.; Zhang, X.; Liu, K.; Zhang, J.; Wu, X.; Zhu, J.; Tu, J. Map-based cloning of a novel rice cytochrome P450 gene CYP81A6 that confers resistance to two different classes of herbicides. Plant Mol. Biol. 2006, 61, 933-943. [CrossRef] [PubMed]

31. Haughn, G.W.; Smith, J.; Mazur, B.; Somerville, C. Transformation with a mutant Arabidopsis acetolactate synthase gene renders tobacco resistant to sulfonylurea herbicides. Mol. Gen. Genet. 1988, 211, 266-271. [CrossRef]

32. Li, H.; Freeling, M.; Lisch, D. Epigenetic reprogramming during vegetative phase change in maize. Proc. Natl. Acad. Sci. USA 2010, 107, 22184. [CrossRef] [PubMed]

33. Lin, Z.; Liu, M.; Damaris, R.N.; Nyong'a, T.M.; Cao, D.; Ou, K.; Yang, P. Genome-Wide DNA Methylation Profiling in the Lotus (Nelumbo nucifera) Flower Showing its Contribution to the Stamen Petaloid. Plants (Basel) 2019, 8, 135. [CrossRef] [PubMed]

34. Wang, W.; Qin, Q.; Sun, F.; Wang, Y.; Xu, D.; Li, Z.; Fu, B. Genome-Wide Differences in DNA Methylation Changes in Two Contrasting Rice Genotypes in Response to Drought Conditions. Front. Plant Sci. 2016, 7, 1675. [CrossRef] [PubMed]

35. Goto, K.; Meyerowitz, E.M. Function and regulation of the Arabidopsis floral homeotic gene PISTILLATA. Genes Dev. 1994, 8, 1548-1560. [CrossRef]

36. Peragine, A.; Yoshikawa, M.; Wu, G.; Albrecht, H.L.; Poethig, R.S. SGS3 and SGS2/SDE1/RDR6 are required for juvenile development and the production of trans-acting siRNAs in Arabidopsis. Genes Dev. 2004, 18, 2368-2379. [CrossRef] [PubMed]

37. Simon, S.A.; Meyers, B.C. Small RNA-mediated epigenetic modifications in plants. Curr. Opin. Plant Biol. 2011, 14, 148-155. [CrossRef] [PubMed]

38. Mathieu, O.; Bender, J. RNA-directed DNA methylation. J. Cell Sci. 2004, 117, 4881-4888. [CrossRef]

39. Baulcombe, D. RNA silencing in plants. Nature 2004, 431, 356-363. [CrossRef]

40. Baulcombe, D.C. Unwinding RNA silencing. Science 2000, 290, 1108-1109. [CrossRef]

41. Van der Krol, A.R.; Mur, L.A.; Beld, M.; Mol, J.; Stuitje, A.R. Flavonoid genes in petunia: Addition of a limited number of gene copies may lead to a suppression of gene expression. Plant Cell Online 1990, 2, 291-299. 
42. Smith, C.; Watson, C.; Bird, C.; Ray, J.; Schuch, W.; Grierson, D. Expression of a truncated tomato polygalacturonase gene inhibits expression of the endogenous gene in transgenic plants. Mol. Gen. Genet. 1990, 224, 477-481. [CrossRef] [PubMed]

43. Elmayan, T.; Vaucheret, H. Expression of single copies of a strongly expressed $35 \mathrm{~S}$ transgene can be silenced post-transcriptionally. Plant J. 1996, 9, 787-797. [CrossRef]

44. Wu, L.; Mao, L.; Qi, Y. Roles of DICER-LIKE and ARGONAUTE Proteins in TAS-Derived Small Interfering RNA-Triggered DNA Methylation. Plant Physiol. 2012, 160, 990-999. [CrossRef] [PubMed]

45. Weinhold, A.; Kallenbach, M.; Baldwin, I.T. Progressive 35S promoter methylation increases rapidly during vegetative development in transgenic Nicotiana attenuata plants. BMC Plant Biol. 2013, 13, 99. [CrossRef] [PubMed]

46. Li, J.; Brunner, A.M.; Shevchenko, O.; Meilan, R.; Ma, C.; Skinner, J.S.; Strauss, S.H. Efficient and stable transgene suppression via RNAi in field-grown poplars. Transgenic Res. 2008, 17, 679-694. [CrossRef]

47. Scheid, O.M.; Paszkowski, J.; Potrykus, I. Reversible inactivation of a transgene in Arabidopsis thaliana. Mol. Gen. Genet. 1991, 228, 104-112. [CrossRef]

48. Otagaki, S.; Kawai, M.; Masuta, C.; Kanazawa, A. Size and positional effects of promoter RNA segments on virus-induced RNA-directed DNA methylation and transcriptional gene silencing. Epigenetics 2011, 6, 681-691. [CrossRef]

49. Zhang, X.; Yazaki, J.; Sundaresan, A.; Cokus, S.; Chan, S.W.-L.; Chen, H.; Henderson, I.R.; Shinn, P.; Pellegrini, M.; Jacobsen, S.E. Genome-wide High-Resolution Mapping and Functional Analysis of DNA Methylation in Arabidopsis. Cell 2006, 126, 1189-1201. [CrossRef]

50. Kooter, J.M.; Matzke, M.A.; Meyer, P. Listening to the silent genes: Transgene silencing, gene regulation and pathogen control. Trends Plant Sci. 1999, 4, 340-347. [CrossRef]

51. Meyer, P.; Saedler, H. Homology-dependent gene silencing in plants. Annu. Rev. Plant Biol. 1996, 47, $23-48$. [CrossRef] [PubMed]

52. Dun, X.; Zhou, Z.; Xia, S.; Wen, J.; Yi, B.; Shen, J.; Ma, C.; Tu, J.; Fu, T. BnaC. Tic40, a plastid inner membrane translocon originating from Brassica oleracea, is essential for tapetal function and microspore development in Brassica napus. Plant J. 2011, 68, 532-545. [CrossRef] [PubMed]

53. Yi, B.; Zeng, F.; Lei, S.; Chen, Y.; Yao, X.; Zhu, Y.; Wen, J.; Shen, J.; Ma, C.; Tu, J. Two duplicate CYP704B1-homologous genes BnMs1 and BnMs2 are required for pollen exine formation and tapetal development in Brassica napus. Plant J. 2010, 63, 925-938. [CrossRef] [PubMed]

54. Frommer, M.; McDonald, L.E.; Millar, D.S.; Collis, C.M.; Watt, F.; Grigg, G.W.; Molloy, P.L.; CL, P. A genomic sequencing protocol that yields a positive display of 5-methylcytosine residues in individual DNA strands. Proc. Natl. Acad. Sci. USA 1992, 1827-1831. [CrossRef] [PubMed]

55. Bao, N.; Lye, K.-W.; Barton, M.K. MicroRNA binding sites in Arabidopsis class III HD-ZIP mRNAs are required for methylation of the template chromosome. Dev. Cell 2004, 7, 653-662. [CrossRef] [PubMed] 